Neth. J. Agric. Sci., 15 (1967) : 161-169

\title{
Patterns of choice behaviour on peasant farms in Northern Nigeria
}

\author{
H. A. Luning \\ Department of Agricultural Economics of the Tropics and Sub-tropics, Agricultural \\ University, Wageningen, The Netherlands
}

Received 8 September, 1966

\begin{abstract}
Summary
In this article an analysis is presented of a budget study on farm data from Northern Nigeria's groundnut farmers. The following resource allocation model appears to fit best the local behavioural patterns: Satisfaction $=\mathrm{f}$ (Self-sufficiency in food, maintenance of soil fertility, cash income). The 'maximization of satisfaction' hypothesis is tested and accepted. However, there is one restriction, namely that in the present farming system no allowance appears to have been made for the long-term maintenance of soil fertility, which should safeguard continuous, future returns.
\end{abstract}

\section{Introduction}

In the literature on under-developed areas, opposing views have been presented on the relevancy of certain tenets of economic theory. Some scholars contend that the institutional behaviour of the people in these areas is characterized by the absence of a motive for economic gain (e.g. Dalton, 1961, 1962; Boeke, 1953) and that this aspect of economic theory cannot be fruitfully applied.

Allegedly, non-economic factors dominate the motives and activities of the people concerned. Others (e.g. Berg, 1961; Dean, 1965; W. O. Jones, 1960; Schultz, 1964) have contested the above contentions and they have collected a considerable body of empirical evidence to support the view that economic theory is useful in the study of decision making in traditional peasant societies.

In this article a quantitative analysis on a micro-level is presented on the farming pattern as encountered in the main groundnut-cultivated area in Northern Nigeria during the farming season of 1962 .

The hypothesis is tested that farmers are led by profit motives in allocating their scarce resources. However, in a hardly specialized economy, as described here, the profit motive has to be subjected to certain environmental restrictions. It is outlined that in order to obtain highest, continuous net returns it is necessary to safeguard the family's food subsistence requirements and the maintenance of soil fertility.

\section{Natural environment and farming pattern}

Northern Nigeria's principal groundnut-belt is located within the provinces of Kano, Katsina and Eastern Sokoto. 
The surveyed area is within the Sudan zone of the West-African savannah as described by Keay (1959). Rainfall is of the uni-modal type and precipitation is from 25 to 35 inches between May and October with August as the wettest month. The rain is occasionally delayed by one month and often ends abruptly in the second half of September. There is a risk of a bad season about once every eight years due to the uneven distribution of rain at the beginning of this season.

The soil is predominantly of the light sandy type, of low to medium fertility and easily tilled. The plains of Hausa-land are smoothly rolling and on the bottom of the slopes usually loam and clay deposits are found, where water is retained during the prolonged dry season. Because of the availability of water the latter 'pockets' are scarce and are in great demand for the cultivation of sugarcane, rice, tobacco, maize, onions, peppers etc. Owing to population pressure in this area the sandy uplands are being cultivated more or less permanently and fallow land is rare. It is also an important livestock area but grazing is restricted to the shallow patches of soils which are considered unsuitable for farming, and to areas specifically set aside by the authorities for the purpose of grazing and the collection of firewood.

Farming is traditional hoe farming and only a very few people have a plough and bullocks; again practically no use is made of artificial fertilizers in the area studied. Of the main foodcrops (millet, guineacorn, cowpeas) and the principal cash crop (groundnuts), local varieties - known for ages - are being used; none of the improved strains have been introduced on a sufficiently large scale to make even the slightest impact. It is for cotton only that the research tested variety is universally distributed and cultivated. Over $90 \%$ of the area under crops is inter-cropped. The most common combinations are millet-guineacorn-cowpeas, groundnuts-guineacorn and/or millet. No irrigation is practised on upland crops.

The Hausa farmers realize that under a system of permanent cultivation with low initial fertility the maintenance of soil fertility is important. Farmyard manure and all kinds of organic material are collected. Usually the fields adjacent to the village receive manure but not enough is available for the distant fields.

\section{The survey method}

The characteristics of the peasant farming systems in Tropical Africa often cause formidable difficulties in obtaining quantitative data. For our area of study little basic information was available on relevant farm inputs and outputs. For instance, the farmers lacked a specified standard of land measurement. This meant that all farms (often of a very irregular shape) had to be visited for measurement. Quantities of products were expressed as bundles of grain, bags of groundnuts, sheets of cotton and baskets of cowpeas, weight, size and volume of which were not always uniform. Six villages, representative of the eastern part of Sokoto Province, were choosen for the study. An agro-economic survey aimed at collecting basic data on the farming structure was conducted, covering between 30-40 randomly selected informants per village. In addition, in each village a study was made of five families of whom daily farm records were kept (including daily labour activities) from 1st of May until the end of December 1962. This period covered the complete agricultural year for major upland crops. At harvest time all farm products of these farms were weighed and the area cultivated measured by chain-surveying. Selection was by chance and comparison with results of the larger survey sample showed that these cases may be 
considered as representative for each area. After careful scrutinizing, the records of 28 out of the total of 30 farm enterprises with a farm size ranging from 1.5 to 25 acres were considered for further analysis.

\section{The resource allocation model}

The problem under consideration is: how and what decisions regarding resource use are made within the present farming system and to what extent does the behavioural pattern concur with such objectives as maximization of the family income as found in a completely commercialized economy? As has been emphasized in a previous section: the farming system in this area is traditional and static. The benefits of agricultural research, organization and education, have hardly touched it; main contributions as sponsored by the Government lie in the organization of groundnut marketing and in the provision of cotton seed.

Before the study of resource allocation be attempted the following assumptions have to be made:

1) There are a number of resources available and certain limitations to them, to which farmers have to adjust themselves individually.

2) Resource allocation is studied within the present and static framework described above and changes are not anticipated in the near future.

3) A free competitive market for agricultural products is assumed. Inputs, however, are more or less fixed for each individual enterprise. It is taken that farmers had a good knowledge of input and output prices and that shifts in these prices, but for the seasonal fluctuations within the year, were insignificant.

Having developed the framework within which the problem is set, it is necessary now to clarify the concept of profit motives.

The profit motive is usually defined within the context of a commercialized economy as maximization of net revenue. This objective provides a good working basis for economic analysis, though it is conceded that it is of lower order than the more comprising objective of maximization of satisfaction.

It is proposed here that the latter objective is more relevant and appropriate in the above outlined conditions, namely a hardly specialized and rather stagnant economy, in which the family is simultaneously the production and consumption unit.

The following model is presented for testing:

Satisfaction $=\mathrm{f}$ (Self-sufficiency in food, maintenance of soil fertility, cash income).

The hypothesis is formulated as follows: existing resources at the farm level are being employed in such a way that maximization of satisfaction is aimed at: this is taken here as identical with maximization of cash income, subject to the safeguarding of the family subsistence requirements and to the long-run maintenance of natural resources.

In view of local conditions it is necessary to include the requirement of food selfsufficiency. In fact this is a mi.jor policy object of the government of Northern Nigeria, which has been stressed time and again. It has been mentioned previously that bad seasons frequently occur; near-famine conditions in these parts of Northern Nigeria during the 1949-1950 seasons are still vividly remembered (Grove, 1957). As for the maintenance of soil fertility, research in Northern Nigeria has shown that, in order to safeguard continuous returns, organic matter is of vital importance in the 
grain/groundnut areas under continuous cultivation (E. Jones, 1960). In fact windand water erosion form a grave threat to the present natural resources of this area, which is rapidly becoming occupied under the impact of the increase in population.

\section{The method of farm budgetting}

Since the study is focussed on the choice between competitive products a suitable technique had to be chosen for testing the hypothesis concerning this product-product relationship. Both linear programming and farm budgetting qualified as a tool of analysis. As the set of resource restrictions and the number of alternative processes was relatively small, preference was given to the less elaborate method of farm budgetting.

\section{Objective}

The objective is stated as the attainment of maximum satisfaction. This has been worked out in the hypothesis.

\section{Alternative processes}

The principal choice to the farmer in this area is whether to grow millet and/or guineacorn (often interplanted later in the season with cowpeas to fill vacant spaces) or to cultivate groundnuts. Cultivation is done on hand-made ridges and prepared after the rains have started. All crops compete for labour especially during the month of June and July as planting, cultivation and weedings have to be carried out simultaneously. Late weeding appears to be the major yield depressing factor in the present farming system. Groundnuts give higher returns per acre but variable costs are somewhat higher and this crop requires comparatively more labour during the crucial months of june and July. The activities on the small irrigated valley plots have been excluded from the analysis as little interference with upland farming occurs.

\section{Restrictions}

Land. The farm acreage of the individuals in the survey year is considered to be fixed.

Labour. Labour is family labour which has been recorded daily and converted into man equivalent days. Little farmwork was carried out by women. Additional labour is hired (either on daily contract or as task allotment) at peak periods.

The labour data can be divided into three main categories:

a) Time devoted to the main (upland) farming operations.

b) Other agricultural activities (including livestock care).

c) Non-agricultural activities such as domestic commitments, secondary occupations and social obligations.

In the following analysis it is taken that time spent on categories b) and c) were either strictly necessary or equally profitable as time allocated to the main farming operations. Although we have no such proof, personal observation of the system and some information collected on remuneration in secondary occupations makes this quite a realistic starting point. Thus in each individual case the recorded number of days 
Table I Basic data for budgetting

\begin{tabular}{lcr}
\hline Item & Millet/guineacorn-cowpeas & Groundnuts \\
& & \\
Yield per acre & $860 \mathrm{lb}$. unthreshed grain & $780 \mathrm{lb}$. undecorticated \\
Gross return per acre & 109 shillings & 128 shillings \\
Variable costs per acre (seed, implements) & 6 shillings & 13 shillings \\
June labour requirements per acre & 7 man days & 8 man days \\
July labour requirements per acre & 6 man days & 8.5 man days
\end{tabular}

under category a) was taken as the maximum available amount of labour to be devoted to this kind of work. As June as July are the crucial months only these have been considered as restrictive.

Money outlay. Liquid assets were important in connection with three items: the purchase of groundnut seed, purchase and repairs of the simple implements used and the hiring of additional labour.

The farmers interviewed usually did not retain any groundnuts for seed and they borrowed seed at considerable rate of interest. Cash outlays on farm implements were small and the cost of repairs by local blacksmiths could be paid in kind at harvest time. However, the employer had to pay the labourer immediately on completion of the work.

It is assumed that the amount of labour hired is maximum under existing conditions of money scarcity and that it is efficiently used ${ }^{1}$. Personal interviews with local people bear out this contention. Requests for the establishment of cooperative societies were made mainly with the purpose in mind to be able to employ extra labour during the crucial periods. Thus in many instances labour is limiting the potential of the system.

The basic data for budgetting, representing averages for the area are given in Table 1 .

\section{Budgetting of the individual enterprises}

The hasic data presented in Table 1 have been used in budgetting the 28 farm enterprises. The results are shown in Table 2 .

\section{Groundnuts}

In order to test our allocation model as regards the planned and actual balance between food- and cash-crop production, the null-hypothesis posed for groundnuts is, that there is no difference between the planned acreage and actual acreage under this crop.

Using Student's $t$-distribution after applying Bessel's correction to obtain a best esti-

1 An indication of efficient resource use was established through calculation of the marginal productivity of labour. The ratio: marginal value product of labour to its marginal factor cost (i.e. the prevailing wage rate) was found to be not significantly different from 1.0 . This means that the return from employing the last unit of labour was equal to its cost. 
H. A. LUNING

Table 2 Planned farms and actual farming pattern in the groundnut belt of Northern Nigeria (in acres)

\begin{tabular}{|c|c|c|c|c|c|}
\hline \multirow{3}{*}{$\begin{array}{l}\text { Code } \\
\text { No. }\end{array}$} & \multicolumn{3}{|c|}{ Millet, guineacorn, cowpeas } & \multicolumn{2}{|c|}{ Groundnuts } \\
\hline & \multicolumn{2}{|c|}{ planned } & \multirow{2}{*}{$\begin{array}{c}\text { actually } \\
\text { used } \\
\text { acreage }\end{array}$} & \multirow[t]{2}{*}{ planned } & \multirow{2}{*}{$\begin{array}{c}\text { actual } \\
\text { acreage }\end{array}$} \\
\hline & $\begin{array}{l}\text { required } \\
\text { for food }\end{array}$ & non-use & & & \\
\hline 1 & 4.0 & 2.5 & 9.2 & 3.5 & 0.8 \\
\hline 2 & 4.5 & 1.1 & 5.1 & 3.3 & 3.8 \\
\hline 3 & 3.6 & - & 3.3 & 2.8 & 3.1 \\
\hline 4 & 2.0 & - & 1.4 & 0.0 & 0.6 \\
\hline 5 & 5.0 & - & 4.8 & 1.6 & 1.8 \\
\hline 6 & 5.4 & 1.4 & 8.3 & 3.5 & 2.0 \\
\hline 7 & 2.7 & - & 1.0 & 0.7 & 2.4 \\
\hline 8 & 3.6 & - & 4.6 & 1.3 & 0.3 \\
\hline 9 & 3.7 & - & 3.6 & 0.1 & 0.2 \\
\hline 10 & 5.1 & 0.4 & 5.2 & 2.3 & 2.6 \\
\hline 11 & 8.0 & 1.7 & 11.0 & 5.6 & 4.3 \\
\hline 12 & 3.0 & 1.2 & 5.2 & 2.7 & 1.7 \\
\hline 13 & 9.0 & 6.8 & 16.8 & 5.2 & 4.2 \\
\hline 14 & 5.5 & 0.7 & 7.1 & 2.6 & 1.7 \\
\hline 15 & 6.0 & 2.2 & 9.5 & 4.6 & 3.3 \\
\hline 16 & 9.0 & - & 9.8 & 5.1 & 4.3 \\
\hline 17 & 5.0 & - & 4.9 & 2.9 & 3.0 \\
\hline 18 & 5.5 & - & 5.3 & 1.7 & 1.9 \\
\hline 19 & 5.6 & - & 6.5 & 5.7 & 4.8 \\
\hline 20 & 7.2 & 7.8 & 14.6 & 10.0 & 10.4 \\
\hline 21 & 2.4 & 2.6 & 6.4 & 3.6 & 2.2 \\
\hline 22 & 3.2 & 2.9 & 4.6 & 0.9 & 2.4 \\
\hline 23 & 3.6 & 0.1 & 4.5 & 3.0 & 2.2 \\
\hline 24 & 4.4 & - & 4.7 & 2.2 & 1.9 \\
\hline 25 & 4.0 & 1.8 & 5.2 & 0.4 & 1.0 \\
\hline 26 & 3.6 & 3.4 & 4.3 & 0.7 & 3.4 \\
\hline 27 & 1.5 & - & 1.3 & 0.0 & 0.2 \\
\hline 28 & 2.8 & - & 1.9 & 0.8 & 1.7 \\
\hline Total & 128.9 & 36.6 & 170.1 & 76.8 & 72.2 \\
\hline
\end{tabular}

mate of the population variance, $\hat{\sigma}=S \sqrt{ }\{n /(n-1)\}$, it was found that the significance of difference had to be firmly rejected $\left(t=0.75,27\right.$ degrees of freedom) ${ }^{2}$.

\section{Grains}

In accordance with the objectives, firstly the acreage required for family grain consumption was established for each enterprise. The age composition of the family was known and thus the number of adult equivalent consumption units for each family could be calculated.

This was done according to recommendations as laid down by the then Federal Adviser on Nutrition, who also provided estimates of daily grain consumption per adult

2 Prior to Student's $t$-test it was ascertained that the variances of the two samples were identical (Snedecor's $F$-test), which indicates that they are independent estimates of the same population variance. 
consumption unit for the various parts of Northern Nigeria (Baldwin et al., 1957). Figures on average grain production per acre over a long period were available.

Required acreage for food (with allowance made for seed and wastage) is presented in Table 2, second column. Whenever labour was in short supply, it was assumed that the excess acreage was to be left in fallow, this being the best known provision for fertility maintenance. These figures are shown in the third column. The actually used acreage under grain is given in the subsequent column. The null-hypothesis now is, that there is no difference between required and actual planted acreage under grain. Using the same method as applied to groundnuts, (applying the $F$-test) it was found that the null-hypothesis as presented above, is not valid

\section{Discussion}

On the whole the balance between acreage under cash- and food crops has been such that highest possible net income has been achieved. However, all land not allocated for the cash crop has been used for grain. No land has been left in fallow.

The reason is that yields of grain crops are subject to wide variations, as they are planted some time before the cash crops. Risks are great and the farmer tends to plant as large an acreage as possible. This explains the significant difference between actual grain acreage and the theoretically calculated one, which took account of some kind of soil fertility maintenance. It is also quite possible that a short rest period is not even worthwhile economically.

The general picture, as presented above conceals wide variations.

The following analysis of individual cases sheds light on the variation in behaviourial patterns. The amount of labour (family and hired) was clearly not sufficient for optimum results per acre in many cases (for example No. 6, 13, 20, 22, 26). Subsequently yields were often moderate or low but returns per unit of available labour high; hence the latter criterion, i.e. labour productivity is the key for judging the effectiveness of the system in these cases ${ }^{3}$. Such risks of low labour input were taken only in the case of grain crops, where a small capital outlay and a smaller demand on labour during the crucial period are required.

In this context the following observation is of interest. In the beginning of the rainy season a common disease in the area is the incidence of guineaworm, which often debilitates a considerable part of the population. It occurs in places where water contamination is rampant. Families, thus stricken (No. 1, 21) then planted a greatly decreased area of groundnuts and concentrated on the less input-demanding graincrops. Some farmers with a large family labour potential and with enough cash to employ additional labour, cultivated a larger acreage of groundnuts than planted, while falling behind in required grain acreage (No. 4, 7); as their total acreage was anyhow low, the heavier dressing of manure led to a significant higher land productivity. Others (No. 22, 26, 28) merely took the risks of low and very low returns per acre. A comparison of the individual enterprises shows an enormous variation mainly because of the apparent differences in the objective. Thus the amount of labour varied

3 Detailed analysis of the 'crop-mix' points to a marginal labour productivity which is positive even on farms with a low land/labour ratio - and which is approximatively equal to the wage rate (Luning, 1964). 
from 26 to 70 man days per acre, indicating considerable shifts along the aggregate production function 4 .

This is definitely connected with the almost rigidly fixed amount of resources: some families find themselves with a relatively small acreage and abundant labour. They apply a large quantity of inputs, including the application of manure on a small area, while others with few resources beyond a relatively large acreage still fully use their total farmland. However, in the latter case of maximization of the returns to labour the question is in order whether these short run objectives are tenable in the future. To the observer of the depressive evidence of gully, sheet- and wind-erosion - often on a large scale - the answer must be firmly negative.

The present short-run rational behaviour may in the not too distant future present serious difficulties. Farmers are aware of it to a certain extent but at present our basic knowledge of fallow practices and management of pasture is still so scanty that attractive alternatives cannot be presented to the people of the area.

Another example of profit maximization (cash-income) has been observed in the southern villages of the main groundnut belt. The climatological conditions are such that cultivation of cotton may be possible. Hardly any time is available to prepare labourconsuming ridges in June and July and therefore this crop is often interplanted with sole millet. Planting of cotton takes place much later than recommended because of the stress of work on grain crops and groundnuts.

Depending on the rainfall, in some years comparatively reasonable returns (200-500 lb./acre) are achieved.

However, it is considered a chance crop which may fail completely but on the other hand may absorb otherwise idle labourtime from August till January.

\section{Conclusions}

The behavioural pattern in these communities tend to emphasize rational features. After allowance has been made for the family's basic food requirements it is shown that the difference between the acreage of groundnuts planned along lines of maximization of cash income and the actually cultivated area, is not significant. As for grain, all resources are fully used. This leads to different objectives, i.e. maximization of returns per acre or per man day, depending on the individually owned resources at hand. A relatively small cash outlay is necessary for grain cultivation and thus the risks tend to be much smaller than in the case of groundnuts. However, serious doubts arise whether the present short-run view, which does not make sufficient allowance for the maintenance of soil fertility, can be upheld. On the other hand, agricultural research has not yet provided the answers on how the long-term maintenance could be brought about by the farmers of this area.

4 A simple production function of the Cobb-Douglas type was fitted to the farm data. With $Y$ the total production, $X_{1}$ the acreage under crops and $X_{2}$ as the number of man days worked the following relation was established:

$$
Y=1.531 X_{1}^{0.6117} \times X_{2}{ }^{0.3832}
$$

$\left(R^{2}=0.8473\right.$, significant according to $F$-test). 


\section{Acknowledgements}

The author is grateful to J. H. L. Joosten, John Sjo and M. H. Khan for their helpful advice and constructive suggestions.

\section{References}

Baldwin, K. D. S., a.o., 1957. Movement of local foodstuffs. Min. of Agriculture, Northern Nigeria. Berg, E. J., 1961. Backward sloping supply functions in dual economies. The African case. J. Econ., $75: 468-491$.

Boeke, J. H., 1953. Economics and economic policy of dual societies, New York.

Dalton, G., 1961. Economic theory and primitive society. Am. Anthropol., 63: 1-25.

Dalton, G., 1962. Traditional production in primitive African economies. Quart. J. Econ., 76 : 360-378.

Dean, E. R., 1965. Economic analysis and African response to price. J. Farm Econ., 42(2) : $402-409$.

Grove, A. T., 1957. Land and population in Katsina Province. Government Printer, Kaduna, Northern Nigeria.

Jones, E., 1960. The importance of organic matter in the fertility of the soils in Northern Nigeria. Min. of Agriculture, Newsletter.

Jones, W. O., 1960. Economic man in Africa. Food Res. Inst., Stanford Univ., $1(2)$.

Keay, R. W. J., 1959. An outline of Nigerian vegetation. Federal Government Printer, Lagos.

Luning, H. A., 1964. The measurement of labour productivity, a case study. Neth. J. Agric. Sci., 12 (4) : 281-290.

Schultz, Th. W., 1964. Transforming traditional agriculture. Yale Univ. Press, New Haven. 